\title{
Application of Experimental Modal Analysis in practice
}

\author{
C. Krämer, C. A. M. de Smet \\ Section Concrete Structures, Swiss Federal Laboratories for Materials Testing and Research (EMPA), CH-8600 Dibendorf, Switzerland
}

\section{BACKGROUND}

In the past few years, the Section Concrete Structures had made use of the so-called Forced Vibration Test (FVT) method and introduced a new system for Ambient Vibration Tests (AVT). The FVT uses a controlled and neasured input to calculate the dynamic behaviour of the structure tested, whereas the AVT makes use of unknown and unmeasured input due to environmental vibrations.

Civil engineering structures generally are heavy structures with low eigenfrequencies. Thus for a successful FVT, a lot of energy must be put into the structure at low frequencies. This leads to heavy exciters with a lot of bulky equipment, and a fair amount of manpower is required to conduct such a FVT. Environmental excitations of a structure are harmful to a FVT if exceeding a certain level. Also, to attach an exciter to a structure can be a tedious and, in some cases, impossible task.

AVT makes use of the naturally available excitation sources. These sources might be coloured in such a way that the identification of the structure's dynamic behaviour might become difficult. It is often stated that an AVT is only possible if all input to a structure is white noise, which means that the input energy is evenly distributed over the frequency band concerned. Experience with some extreme situations has shown that this assumption can be interpreted quite loosely. AVT needs no exciters, which reduces the costs of an AVT considerably in comparison to a FVT on the same civil engineering structure. It is therefore only natural that the team at the Section Concrete Structures has conducted more AVTs in the past than FVTs. Certain promising time domain based techniques might also help to overcome the peak picking and help engineering based identification of a structure's dynamic behaviour for AVT.
In summary, the experience of the Section Concrete Structures has been that both FVT and AVT can be used to establish a reliable basis to correlate a finite element model. FVT might deliver more reliable information for damping and is the only way to do a multi-degree of freedom identification of the dynamics of a structure. A clear advantage of AVT is the cost of a test.

\section{EXAMPLES OF APPLICATION OF EXPERIMENTAL MODAL ANALYSIS (EMA)}

The following example is based on AVT and could also be considered as an example of using EMA for damage detection at a preliminary stage. The tested object is the Swiss Federal Railway "Hardturm" bridge linking Zurich and Wipkingen. The bridge is an old masonry bridge with several bows. Of specific interest were the piers, which in some cases showed heavy cracks in the masonry walls. The number of tracks was to be increased from 2 to 4 . Tearing down the bridge was not possible due to the historical importance of the structure. This raised the question of the load bearing capacity of the cracked and uncracked piers, as well as the actual damage state of the cracked piers. The interlocking of the cracked piers was questionable as well as the contribution to interlocking of the filling material of the piers. This filling material was extremely heterogeneous, bonded by a low content of cement.

\section{METHODOLOGY}

In order to provide a sound basis, the test was set up as a comparison of the dynamic behaviour of an

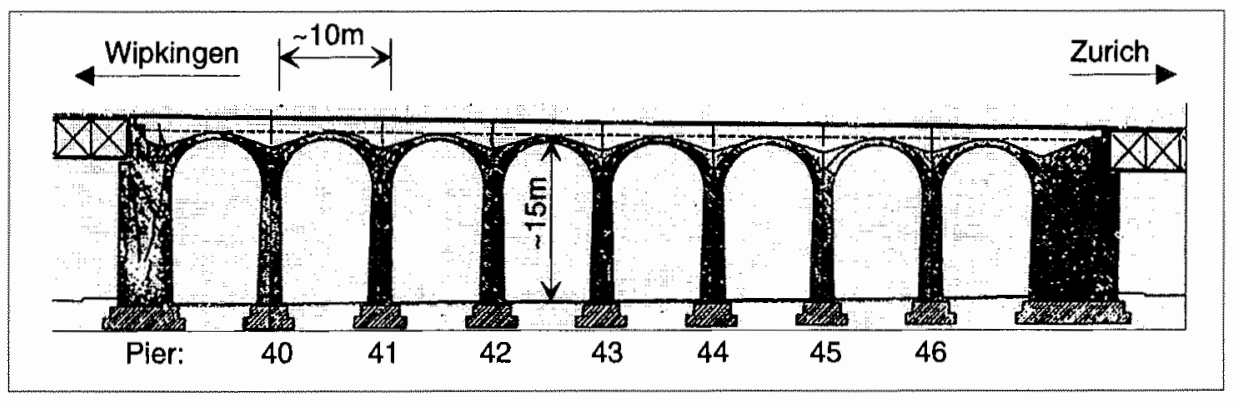

1359-5997/98 ㄷ RILEM
Fig, 1 - Side view of Swiss Federal Railway "Hardturm" bridge, railway line ZurichWipkingen. 


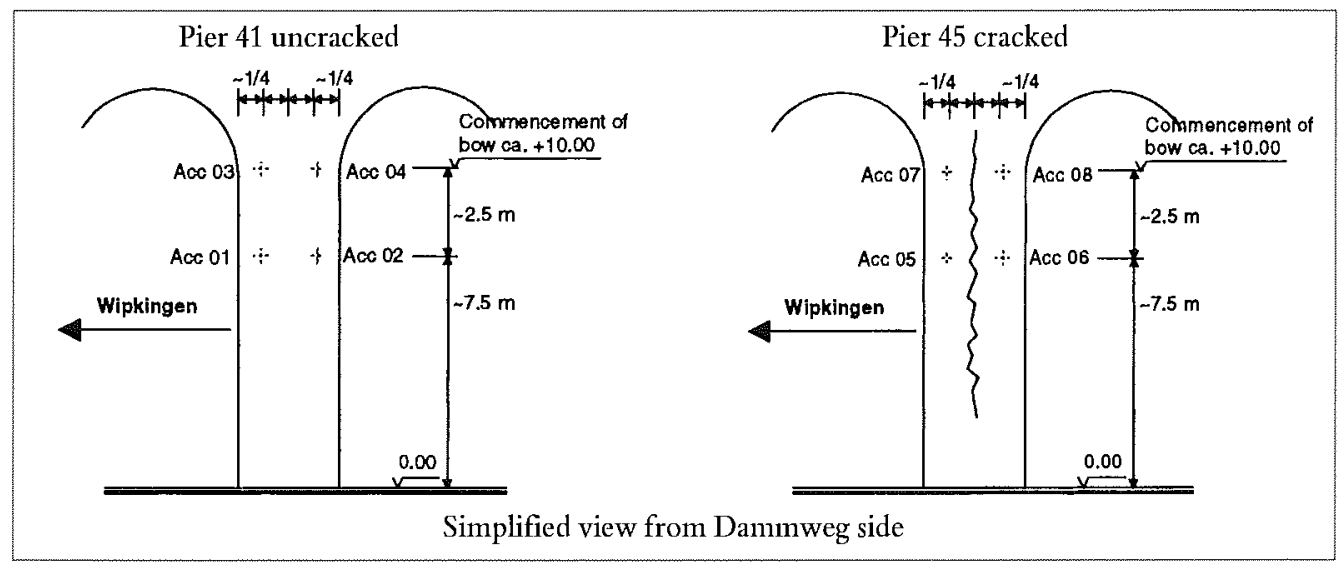

Fig. 2 - Instrumentation of the piers.

uncracked and a cracked pier. Each pier was instrumented with 4 accelerometers measuring horizontally along the bridge axis on one side only.

The point pattern selected compares for pier 41 (uncracked) and pier 45 (cracked). The accelerometer locations were about $+7.5 \mathrm{~m}$ and $+10 \mathrm{~m}$ above ground level. Horizontally, the accelerometers were placed in $1 / 4$ and $3 / 4$ of the faces' width, with the crack of pier 45 about in the middle. The structure was excited by pure ambient influences such as wind, micro-seismic activities and industry activities. Soon it was discovered that the excitation level of pure ambient excitation was not sufficient. Therefore, trains passing over the bridge - omitted for the first measurements - were taken as an excitation source. Although wheel loads could lead to accentuated energy
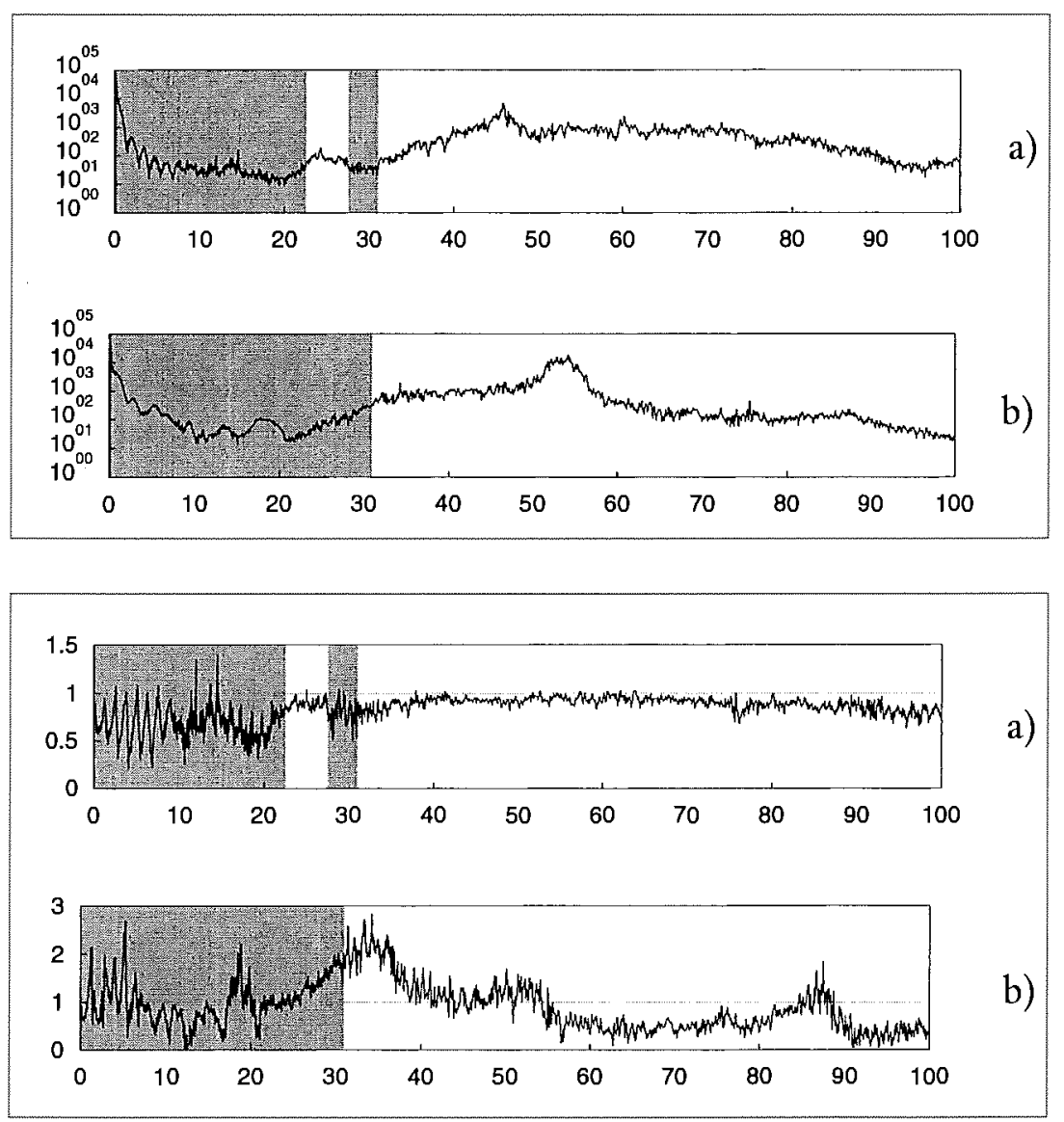

concentration in certain frequency ranges, adverse effects on the results could not be observed.

\section{RESUITS}

The conclusions to be drawn from the tests conducted on the "Hardturm" bridge were based on the comparison of frequency spectra, transfer functions, phase relation, and coherency functions for cracked and uncracked pier accelerometer pairs. The most important diagrams are given hereafter (all plots against frequency in $\mathrm{Hz}$ ). The greyed areas in the plots indicate areas with low confidence.
Fig. 3 - a) Power Spectral Density diagram of Acc 02 pier 41 uncracked; b) Power Spectral Density diagram of Acc 06 pier 45 cracked.
Fig. 4 - a) Transfer function of Acc 01 and Acc 02 pier 41 uncracked; b) Transfer function of Acc 05 and Acc 06 pier 45 cracked. 

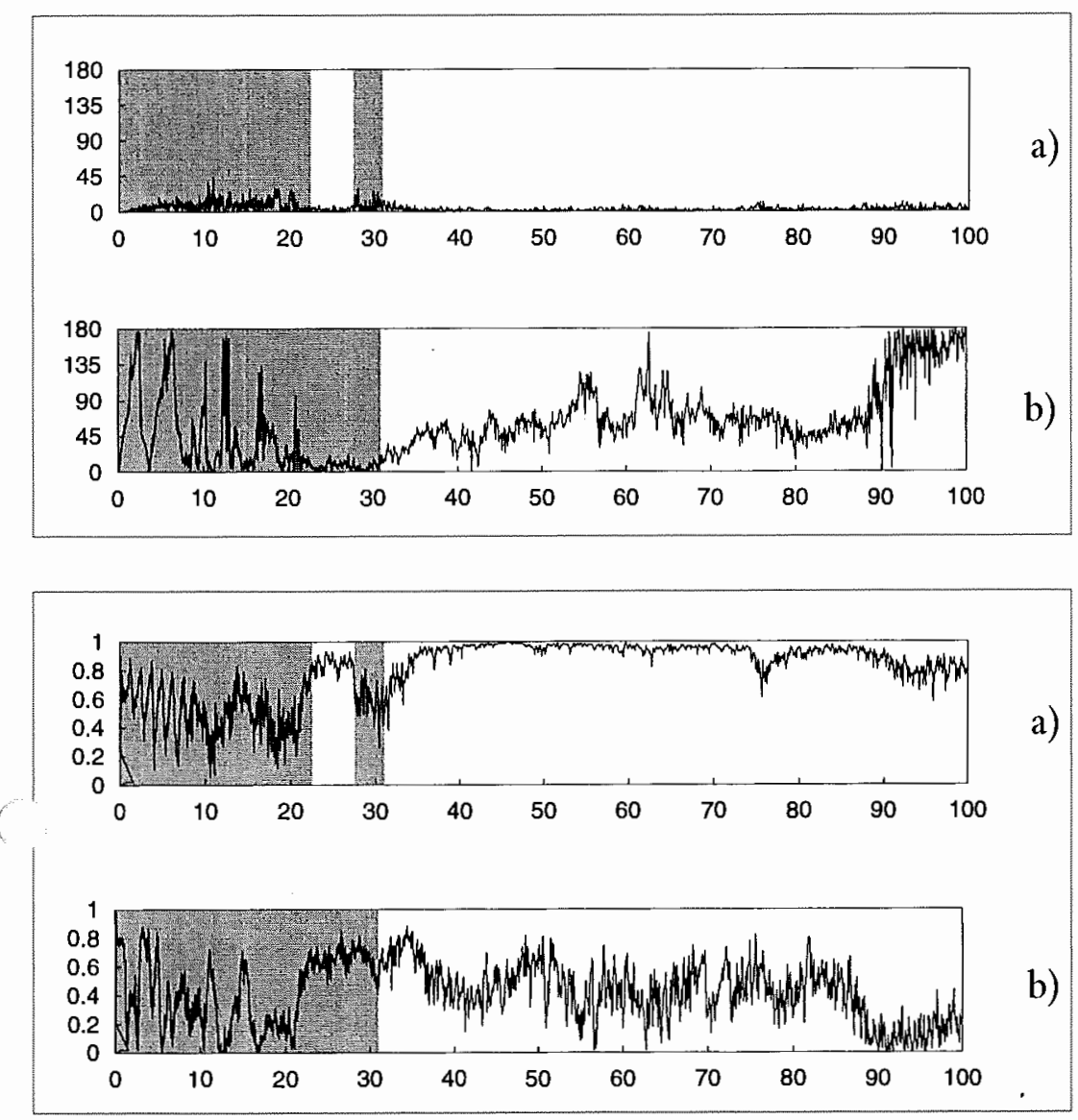

Fig. 5 - a) Phase relation of Acc 01 and Acc 02 pier 41 uncracked; $b$ ) Phase relation of Acc 05 and Acc 06 pier 45 cracked.
Fig. 6-a) Coherence of Acc 01 and Acc 02 pier 41 uncracked; b) Coherence of Acc 05 and Acc 06 pier 45 cracked.

\section{CONCLUSIONS AND DISCUSSION}

From the above figures, characteristic differences between the cracked and the uncracked piers can be derived. The discrepancies become obvious especially at frequencies above about $30 \mathrm{~Hz}$. For the uncracked pier, the transfer function ranges at 1 (Acc 01 moves about the same as Acc 02), the phase is near zero (the points move in phase) and the coherence is close to 1 (the signals correlate). For he cracked pier, almost the contrary observations can be made. Thus, at least a clue is given that the cracked pier's integrity might be severely touched. Interlocking - if ever considered reliable - does not seem to occur.
The test setup was simple and straightforward. Knowing about the damage location certainly helped to select an appropriate instrumentation. However, the conclusions drawn can be relevant for the reinforcement of the piers and have been based on a limited set of information that EMA could provide. It seems that experimental modal analysis, be it FVT or AVT, could become a valuable and objective inspection tool. What remains questionable is whether global dynamic parameters such as modes, eigenfrequencies, etc. are sensitive and local enough to extract similar conclusions when no information about a damage location or type is known. 


\title{
Use of TBM chips as concrete aggregate
}

\author{
Hp. Olbrecht, W. Studer \\ Suiss Federal Laboratories for Materials Testing and Research (EMPA), CH-8600 Dïbendorf, Switzerland
}

\section{INTRODUCTION}

It has been known for some considerable time that available reserves of high-grade alluvial gravel in Switzerland will be practically exhausted in the foreseeable future [1] and that importing it from neighbouring states is hardly a permanent solution to the problem.

It can therefore be described as fortunate that in the near future a large number of tunnels are planned for construction and this will produce an enormous amount of tumnel excavation material.

For obvious reasons, there is more of this "waste product" than is needed for the tunnel construction itself. In addition, it is produced in a form that is very. similar to gravel, especially when the excavation is carried out using tunnel boring machines (TBM).

Treated tunnel excavation material does not differ a great deal from crushed rock, stone chips and ballast. The technique for using this material to make concrete is well known and the fact that it is a full value substitute for alluvial gravel was recently shown dramatically on oil platforms in Norway. Of course, there are more problems associated with the production of concrete using TBM chips than with alluvial gravel. This production demands the application of state-of-the-art concrete technology and knowledge.

The processing of tunnel excavation material is very costly and results inevitably in a material loss which is not desirable for ecological reasons. For these reasons, laboratory investigations were carried out within the framework of the dissertation by Thalmann [2] with the aim of producing concrete using unprocessed tumnel excavation material. These investigations showed that this principle is possible and, under defined conditions, also economically interesting [3].

In order to determine whether these results are applicable in practice, five large scale trials were carried out which are briefly described in the following sections.

\section{LARGE-SCALE TRIALS}

\subsection{Organisation}

As determined by the general aims, the large-scale tests had to be carried out under building site conditions, which meant cooperation with concrete works and building contractors. The fifth test was carried out within the framework of a semester at the Institute of Technology State of Berne, Burgdorf.

During these tests, considerable good-will was required from all partners, as the material was rather unusual and because each had to bear the costs of the work carried out. We would therefore like to take this opportunity of thanking all those involved for their efforts, and we hope that it will pay off in the not too distant future.

\begin{tabular}{|c|l|l|c|c|}
\hline \multicolumn{2}{|c|}{ Designation } & \multicolumn{1}{|c|}{ Source } & $\begin{array}{c}\text { Porosity } \\
\% \text { vol. }\end{array}$ & $\begin{array}{c}\text { Percentage of } \\
\text { non-cubical } \\
\text { grains (8/16) }\end{array}$ \\
\hline I & $\begin{array}{l}\text { Leventina Gneiss } \\
\text { biotite muscovite gneiss }\end{array}$ & $\begin{array}{l}\text { exploration tunnel Polmengo } \\
\text { tunnel metre: } 387 . . .390\end{array}$ & 36.6 & 74 \\
\hline II & Calcareous shale & Kandertal area & 42.1 & 76 \\
\hline III & $\begin{array}{l}\text { Biotite gneiss from } \\
\text { Lucomagno zone, shale- } \\
\text { like and slightly porphyritic }\end{array}$ & $\begin{array}{l}\text { exploration tunnel Polmengo } \\
\text { tunnel metre: } 4600\end{array}$ & 37.2 & 77 \\
\hline IV & Calcareous shale & $\begin{array}{l}\text { exploration tunnel Frutigen } \\
\text { section 100....1500 m }\end{array}$ & 42.3 & 65 \\
\hline V & Silicious limestone & $\begin{array}{l}\text { exploration tunnel Frutigen } \\
\text { tunnel metre: } 6500\end{array}$ & 41.8 & 89 \\
\hline 0 & Alluvial gravel & Swiss midland & 26.0 & 24 \\
\hline
\end{tabular}

\subsection{Determining the concrete composition}

During preparation work for NEAT (New Railway Alpine Transversal) and underground construction work in the Kandertal area of Switzerland, a large amount of TBM excavation material was produced. The aim of the internal EMPA tests was to determine whether this excavation material (see Table 1) could be used as concrete aggregate. The specific target was to produce an easily pumpable concrete with an average cube compressive strength of $35 \mathrm{~N} / \mathrm{mm}^{2}$ after 28 days (strength class 30/20). 